\title{
Adenocarcinoma of Ampulla of Vater Presented as Recurrent Jaundice
}

\author{
Sunil Vitthalrao Jagtap*, Cyrus Dara Jokhi, Digvijay B Patil and Swati S Jagtap \\ Dept of Pathology, KIMS,University,Karad. Maharashtra, India
}

\begin{abstract}
Background: Ampullary carcinoma are relatively uncommon neoplasm which approximately seen in $0.2 \%$ of gastrointestinal carcinomas. Clinically these patient generally present at an earlier stage of the disease. As their strategic location may cause early biliary obstruction.

Case history: A 70 year old male patient was presented with history of pain in abdomen, anorexia and repeated history of jaundice. On ultrasonography and CT scan abdomen-pelvis showed proliferative growth at periampullary area suggestive of ampullary malignancy. Associated cholelithiasis was noted. Patient underwent surgical treatment of pancreaticoduodenectomy with cholecystectomy. On histopathology revealed moderately differentiated intestinal type of adenocarcinoma of ampulla of Vater, Grade II.

Conclusion: We are presenting this uncommon neoplasm for its rarity, recently distinguished subtype on histopathology, clinical behavior and radiological findings.
\end{abstract}

Keywords: Ampullary Carcinoma, Pancreatico-Biliary Tract Neoplasm, Histopathology

\section{Introduction}

The ampulla of Vater is 1.5 to $2 \mathrm{~cm}$ long, flask like cavity into which common bile duct and pancreatic duct open. Ampulla transverse the duodenal wall and opens into duodenal lumen which is surround by pancreas. The area within $2 \mathrm{~cm}$ of the ampulla is called periampullary region. Periampullary cancers account for $5 \%$ of all gastrointestinal cancers, while cancer of ampulla account only $0.2 \%$ with an incidence estimated 3.8 in males and 2.7 in female cases for million population. ${ }^{[1,2]}$ Carcinoma of the ampulla of Vater tends to manifest early due to biliary outflow obstruction. So it is important to detect this lesions and treat early.

\section{Case Hisotry}

A 70 year male patient presented with complaint of pain in abdomen since 4 month which was of dull, nonradiating type, located in right hypochondriac region. Yellowish discoloration of sclera and recurrent icterus was noted . There was no history of vomiting, fever, loose motion. No other associated systemic disease was noted.

On laboratory investigation complete blood count showed Haemoglobin-16 gm\%, Total leucocyte count- 19400/ cumm, polymorphs- $90 \%$, lymphocytes- $10 \%$, platelet count $3.60 \mathrm{lakh} / \mathrm{cumm}$, blood urea $-50 \mathrm{mg} / \mathrm{dl}$, serum creatinine- $3.5 \mathrm{mg} / \mathrm{dl}$, serum bilirubin total $7.7 \mathrm{mg} / \mathrm{dl}$, direct bilirubin $-5.2 \mathrm{mg} / \mathrm{dl}$, indirect bilirubin $-2.5 \mathrm{mg} / \mathrm{dl}$, SGOT$200 \mathrm{IU} / \mathrm{lit}, \mathrm{SGPT}-140 \mathrm{IU} / \mathrm{lit}$, alkaline phosphatase-175
IU/lit, glucose-36 mg/dl. Cancer Antigen (CA) 19.9 was increased upto $264.4 \mathrm{U} / \mathrm{ml}$ (normal 0-31U/ml).

On gastroendoscopy examination ulceroproliferative growth in periampullary area measuring $2 \times 1 \mathrm{~cm}$ was noted which was protruding in duodenum.

On CT scan abdomen-pelvis showed mild to moderate obstructive of extra-intrahepatic biliary radicles suggestive of lower common bile duct malignancy. Diffuse nodularity in periampullary region was noted. Mildly enlarged periportal and peripancreatic lymph nodes. Gall bladder was swollen and lumen filled with multiple gall stones. Our patient underwent Whipple's procedure.

On gross we received segment of duodenum with part of mesentry along with head of pancreas. Duodenum measuring $28 \mathrm{~cm}$ in length. Pancreas measuring $9 \times 5 \times$ $2.8 \mathrm{~cm}$. Serosal surface of duodenum shows congested blood vessels which otherwise is unremarkable. On cutting open luminal surface is unremarkable. Cut section through the ampulla of Vater reveals solid grey white, soft to firm tumor measuring $2.5 \times 1.5 \times 1 \mathrm{~cm}$ (Figure1). Tumor was seen reaching upto the common bile duct and obliterating lumen completely. The pancreas along with pancreatic duct appears unremarkable. The common bile duct measuring 5 $\mathrm{cm}$ in length $0.8 \mathrm{~cm}$ in maximum diameter. On dissection 5 lymph nodes noted at periampullary region. The cholecystectomy specimen $\mathrm{m} .8 .5 \times 4.5 \times 2 \mathrm{~cm}$. On cutting open showed dilatation and flattening of mucosa (Figure 2) and multiple gall stones. 
On microscopic examination section through ampulla of Vater shows a tumor arranged in elongated to illformed glands predominantly (Figure 3). In area tumor was arranged in clusters, cords and papillae. Individual tumor cells are large, round to columnar cells having round to oval hyperchromatic to vesicular nuclei and moderate to scant amount of cytoplasm (Figure 4). Tumor invasion is noted upto muscularis propria. The pancreatic ductular epithelium shows atypical ductal

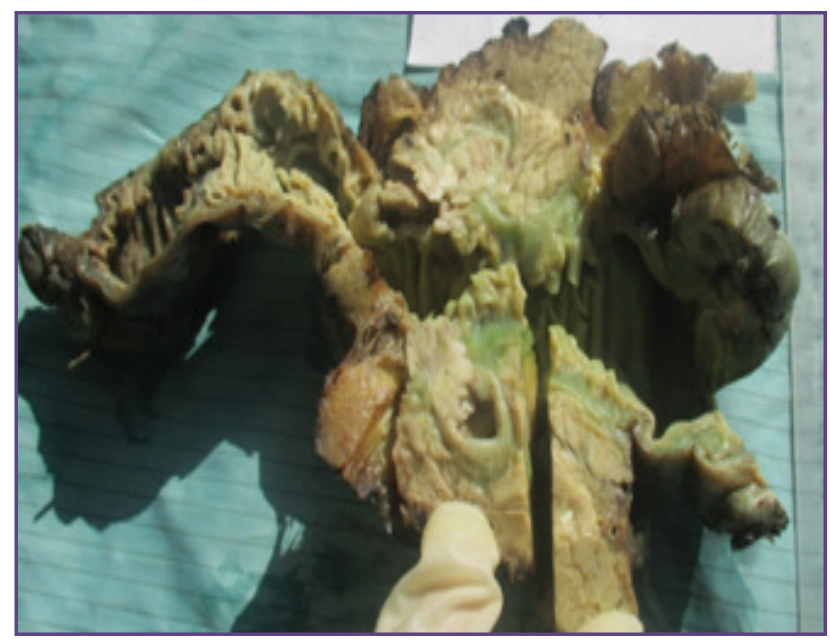

Fig. 1: Gross specimen of pancreaticoduodenectomy showing a tumor at ampulla of Vater.

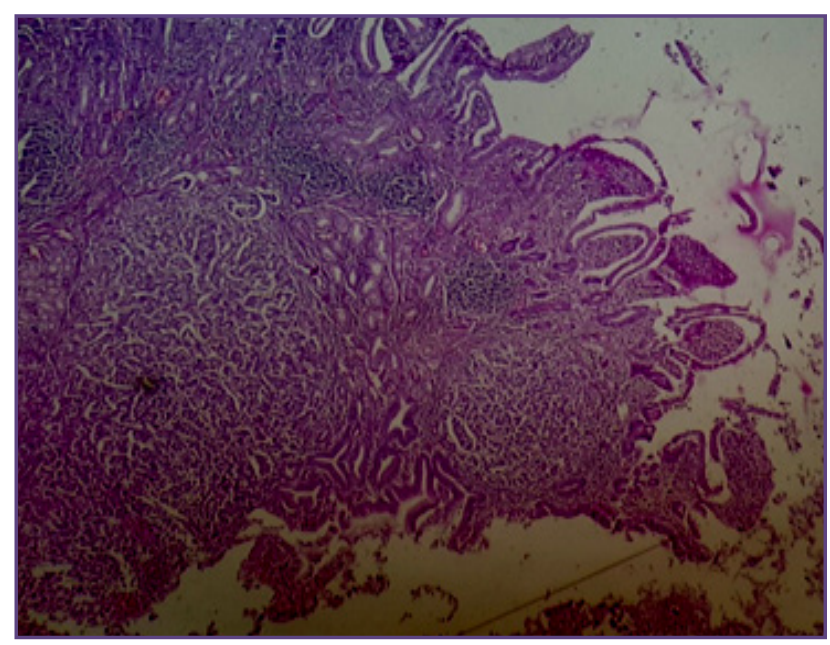

Fig. 3: Photo micrograph showing ampulla of Vater with a tumor arranged in elongated to illformed glands (H \& E stain, 100X).

\section{Discussion}

Ampullary carcinomas are tumor centered in the region of the ampulla of Vater which consists of three anatomical components - the ampulla (common channel), the intra duodenal portion of the bile duct and intra duodenal portion of the pancreatic duct. Based on their epithelium of origin two subtypes of ampullary carcinoma have been recently hyperplasia. However there is no involvement of pancreas. The pancreatic duct appears unremarkable. Pancreatic tissue which shows islet cell hyperplasia in one focus rest of pancreas is unremarkable (Figure 5). The mesentery was unremarkable. The tumor margins and regional lymph nodes were negative for tumor invasion. On histopathology reported as moderately differentiated intestinal type adenocarcinoma of ampulla of Vater.

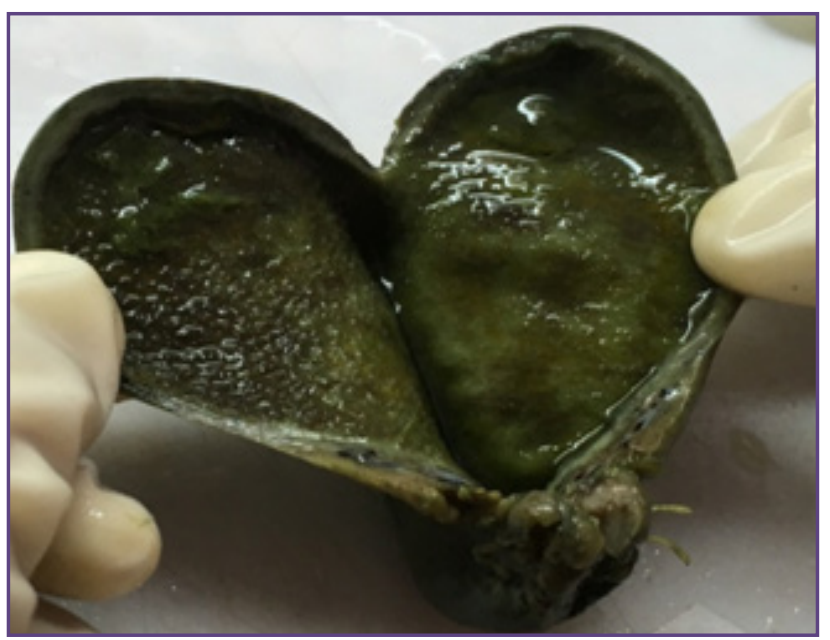

Fig. 2: Gross specimen of cholecystectomy with dilatation and flattening of mucosa.

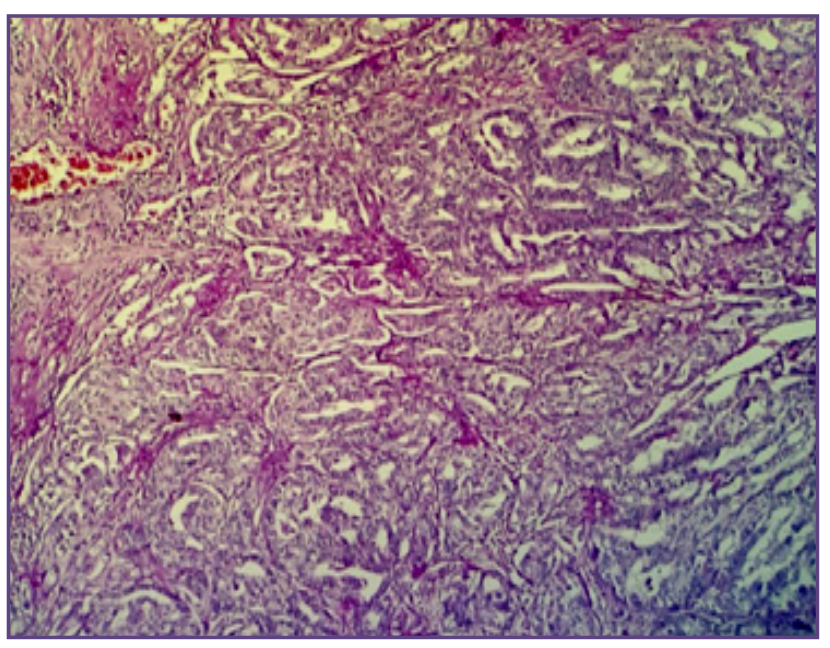

Fig. 4: Photo micrograph showing adenocarcinoma of ampulla of Vater high power view (H \& E stain, $400 \mathrm{X}$ ).

distinguished as - intestinal and pancreatobiliary: ${ }^{[3,4]}$ In our case it is of intestinal ampullary carcinoma originated from the (mucosa ) epithelium of overlying the ampulla. In advanced tumor it is difficult to distinguished tumor origin between ampulla, distal common bile duct or pancreas. In such situation the diagnosis can be rendered as " carcinoma of the pancreato-billiary-ampullary region". 
The clinically most individual are over the age of 60 years. Slightly male predominance is noted. Patient usually present with symptoms suggestive of jaundice, pain in abdomen. There is association of pre-existing amullary adenomas, familial adenomatous polyposis, neurofibromatosis typeI. $^{[5,6]}$ In our case there was no any pre existing cause was noted.

On endoscopic examination our patient showed a single about $2 \mathrm{~cm}$ ulceroproliferative growth in ampullary region extending to duodenal lumen. Most reported invasive adenocarcinoma of ampulla are exophytic.

On microscopy in our case showed moderately differentiated adenocarcinoma with intestinal type differentiation. Usually these tumor shows invasive gland forming tumor with two types - intestinal and pancreaticobilliary. Also a variety of other histologic growth pattern have been reported which includes poorly differentiation, singnet ring, clear cell, mucinous, papillary, hepatoid, neuroendocrine types. ${ }^{[7,8]}$

Differential diagnosis of ampullary carcinoma included cholangiocarcinoma of common bile duct, ampullary villous adenoma. The treatment of choice of ampullary carcinoma is the Whipple procedure. Our patient underwent Whipple's procedure . The prognosis of ampullary carcinoma is significantly better than pancreatic carcinoma. ${ }^{[9,10]}$ Further more in ampullary carcinoma of the intestinal type have better prognosis as compared to pancreatico-billiary type. As pancreatico-billiary type tend to present with late clinical manifestation and in a more advanced stages, regional nodal and perinodal invasion. While intestinal type present earlier due to obstructive manifestation and recurrent jaundice.

The recent series studied showed the overall 5 years survival rate was $25 \%$ has rises to $50 \%$ or above. ${ }^{[11]}$ So it is important to diagnosed cases of ampullary carcinoma of Vater and treat them.

\section{Conclusion}

We are presenting this uncommon neoplasm for its rarity, recently distinguished subtype on histopathology, clinical behavior and radiological findings. As the prognosis of ampullary carcinoma is significantly better than that of pancreatic carcinoma and bile duct carcinoma it is important to diagnosed on histopathology and separate this entity.

\section{References}

1. Benhamiche AM, Jouve JL, Manfredi S, Prost P, Isambert N, Faivre J .Cancer of the ampulla of Vater: results of a 20 -year population-based study, Eur J Gastroenterol Hepatol. 2000 Jan;12(1):75-9.

2. Kim RD, Kundhal PS, McGilvray ID, Cattral MS, Taylor B, Langer B, Grant DR, Zogopoulos G, Shah SA, Greig PD, et al. Predictors of failure after pancreaticoduodenectomy for ampullary carcinoma. J Am Coll Surg. 2006;202:112-119.

3. Zhou H, Schaefer N, Wolff $M$, et al. Carcinoma of the ampulla of Vater : comparative histologic/ immunohistochemical classification and follow-up. Am J Surg Pathol 2004;28:875-882.

4. Kimura W, Futakawa N, Zhao B. Neoplastic diseases of the ampulla of Vater. J Hepatobiliary Pancreat Surg 2004;11:223-231.

5. Costi R, Carvana P, Sarli I, et al. Ampullary adenocarcinoma in neurofibromatosis type I. Case report and literature review. Mod Pathol 2001;14:1169-74.

6. Wagner PI, Chen YT, Yantiss RK. Immunohistochemical and molecular features of sporadic and FAP-associated duodenal adenomas of ampullary and nonampullary mucosa. Am J Surg Pathol 2008;32:1338-1395.

7. Gardiner GW, Lojrie G, Keith R. Hepatoid adenocarcinoma of the papilla of Vater. Histopathology 1992;20:541-544.

8. Carter JT, Grenert JP, Rubenstein L. Tumors of the ampulla of Vater, histological classification and predictor of survival. J Am Coll Surg 2008,207(2):210-8.

9. Berberat PO, Kunzli BM, Gulbinas A, et al. An audit of outcomes of a series of periampullary carcinoma. Eur J Surg Oncol 2009;35:187-91.

10. Howe JR, Klimstra DS, Moccia RD, et al. Factors predictive of survival in ampullary carcinoma. Ann Surg 1998;228:8794.

11. Kim WS, Choi DW, Choi SH, et al. Clinical significance of pathologic subtype in curatively resected ampulla of Vater. J Surg Oncol 2012;105(3):266-72.

*Corresponding author:

Dr. Sunil vitthalrao Jagtap, Professor, Pathology Dept. KIMS University, Karad. 415110. MaharashtraIndia

Email: drsvjagtap@gmail.com

Financial or other Competing Interests: None. 